06;07

\title{
Влияние режима отжига на свойства терагерцевой фотопроводящей антенны на основе LT-GaAs
}

\author{
(C) С.А. Номоев ${ }^{1}$, И.С. Васильевский ${ }^{1}$, А.Н. Виниченко ${ }^{1}$, \\ К.И. Козловский ${ }^{1}$, А.А. Чистяков ${ }^{1}$, Е.Д. Мишина ${ }^{2}$, \\ Д.И. Хусяинов ${ }^{2}$, А.М. Буряков ${ }^{2, \uparrow}$ \\ ${ }^{1}$ Национальный исследовательский ядерный университет „МИФИ“, \\ Москва, Россия \\ ${ }^{2}$ Московский технологический университет „МИРЭА“, Москва, Россия \\ 『 E-mail: bello16@mail.ru
}

Поступило в Редакцию 3 июля 2017 г.

Методом молекулярно-лучевой эпитаксии выращены пленки LT-GaAs (low temperature gallium arsenide - арсенид галлия, выращенный методом молекулярно-лучевой эпитаксии при низкой температуре роста) на подложках $\operatorname{GaAs}(100)$ при температуре $230^{\circ} \mathrm{C}$ и проведен постростовый отжиг. На поверхности пленок изготовлены фотопроводящие антенны с флажковой геометрией. Получены мощностные зависимости терагерцевого отклика при различных значениях напряжения смещения и температуры постростового отжига. Методом терагерцевой спектроскопии исследованы спектральные характеристики изготовленных фотопроводящих антенн. Определен диапазон оптимальной температуры постростового отжига $\left(670-720^{\circ} \mathrm{C}\right)$ пленок LT-GaAs.

DOI: 10.21883/PJTF.2018.02.45459.16947

Источники и детекторы терагерцевого (THz) излучения являются перспективными компонентами систем высокоскоростной беспроводной связи, медицинской и фармацевтической диагностики, бесконтактного контроля качества материалов и дистанционного обнаружения опасных объектов [1].

В качестве функционального слоя фотопроводящих антенн (ФПА) главным образом используются полупроводниковые материалы. Основным свойством таких материалов должно быть малое время жизни фотовозбужденных носителей заряда. Один из наиболее часто используемых полупроводников - низкотемпературный арсенид галлия 
Параметры отжига структур и интегральная THz-мощность ФПА на их основе

\begin{tabular}{c|c|c|c}
\hline Образец & $\begin{array}{c}\text { Температура } \\
\text { отжига } T_{a n n},{ }^{\circ} \mathrm{C}\end{array}$ & $\begin{array}{c}\text { Время } \\
\text { отжига } t_{a n n}, \min \end{array}$ & $\begin{array}{c}\text { Мощность } \\
\text { THz-отклика } P, \mu \mathrm{W}^{*}\end{array}$ \\
\hline LT-GaAs-1 & 670 & 6 & 5 \\
LT-GaAs-2 & 700 & 6 & 4.2 \\
LT-GaAs-3 & 720 & 6 & 1.4
\end{tabular}

* При напряжении смещения $160 \mathrm{~V}$.

(LT-GaAS). LT-GaAs имеет малое время жизни (1-10 ps) [2] и относительно высокую подвижность фотовозбужденных носителей заряда. Высокая концентрация структурных дефектов LT-GaAs создает глубокие центры, возникающие в процессе роста и постростового отжига благодаря избытку мышьяка. Эти глубокие центры обеспечивают рекордно низкие времена жизни неравновесных носителей [2]. Поэтому при оптическом возбуждении структуры LT-GaAs способны генерировать пикосекундные (и более короткие) электрические импульсы, имеющие спектральный максимум в THz-области [3].

В большинстве исследований по созданию LT-GaAs [4,5] постростовый отжиг проводится в in situ в камере эпитаксиальной установки при температурах до $600^{\circ} \mathrm{C}$ от одной до нескольких минут с избыточным давлением мышьяка $0.5 \%$. При этом возможны процессы частичной потери мышьяка с поверхности, которые можно устранить, например, закрытием поверхности пластиной GaAs. Уоррен с соавторами [6] в качестве фотопроводящего материала использовали LT-GaAs, отожженный при $600^{\circ} \mathrm{C}$. Низкотемпературный арсенид галлия, отожженный

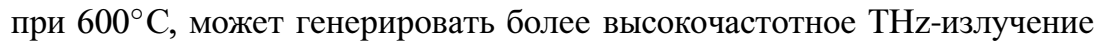
(до $3 \mathrm{THz}$ ) с повышенной мощностью, чем неотожженный LT-GaAs.

Таким образом, несмотря на значительное количество экспериментальных исследований, оптимальные режимы отжига LT-GaAs определены недостаточно. Основная цель настоящей работы - определение оптимальной температуры отжига LT-GaAs для получения максимальной мощности THz-излучения в фотопроводящих антеннах с флажковой

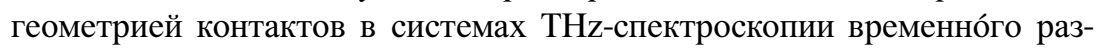
решения. 
Пленки LT-GaAs выращивались на подложках $\mathrm{GaAs}(100)$ методом молекулярно-лучевой эпитаксии [7]. Температура роста LT-GaAs cocтавляла $T_{g}=230^{\circ} \mathrm{C}$. Значение отношения потоков мышьяка $\mathrm{As}_{4}$ и галлия $\gamma\left(\gamma=P_{\mathrm{As}} / P_{\mathrm{Ga}}\right)$ равнялось 19 . Это значение было выбрано в соответствии с исследованиями, проведенными в работе [8], в которой отношение потоков мышьяка и галлия равнялось 20, что намного больше, чем обычное отношение мышьяка к галлию - 6 [9]. Параметры отжига созданных образцов LT-GaAs, а также их обозначения приведены в таблице.

Рост в условиях, близких к стехиометрическим $\left(J_{\mathrm{As}} / J_{\mathrm{GA}} \approx 1\right)$, позволяет даже при весьма низких температурах $\left(T_{g} \approx 150^{\circ} \mathrm{C}\right)$ получать слои LT-GaAs с малой плотностью дефектов и параметрами, близкими к параметрам слоев, выращенных при стандартных температурах. Как отмечается в [10], увеличение потока мышьяка в процессе роста слабо влияет на концентрацию мышьяка в GaAs. Однако в других исследованиях $[8,11]$ приводятся данные о высокой концентрации структурных дефектов As при больших значениях его потока. Поэтому нами выбраны высокие значения $\gamma$, которые позволят создать высокую концентрацию дефектов мышьяка и соответственно при последующем высокотемпературном отжиге сформировать глубокие центры и обеспечить низкое время релаксации носителей заряда в GaAs.

Образцы подвергались отжигу в высоковакуумной камере при температуре $\left(T_{a n n}\right)$ от 670 до $720^{\circ} \mathrm{C}$. Время отжига составило $6 \mathrm{~min}$ в вакууме $10^{-7}$ Torr без стабилизации потоком мышьяка, при этом лицевая сторона структуры плотно закрывалась подложкой GaAs. Достаточно малое время отжига использовалось для того, чтобы предотвратить сильное снижение плотности кластеров мышьяка, а также сегрегацию мышьяка к поверхности структуры и последующее его испарение.

После роста структур на всех образцах методом контактной фотолитографии были сформированы ФПА $\mathrm{Ni} / \mathrm{AuGe} / \mathrm{Ni} / \mathrm{Au}$ с шириной зазора $200 \mu \mathrm{m}$ и флажковой геометрией.

Для измерения абсолютного значения генерируемой мощности THz-излучения ФПА использовалась оптическая установка с пироэлектрическим детектором. На рис. 1 представлены зависимости мощности THZ-отклика ФПА на основе LT-GaAs-1,2,3 от напряжения смещения. На рисунке также указано значение THz-излучения коммерческой антенны Zomega. Видно, что кривая для всех ФПА представляет собой нелинейно возрастающую зависимость (аппроксимация дает зависи-

Письма в ЖТФ, 2018, том 44, вып. 2 


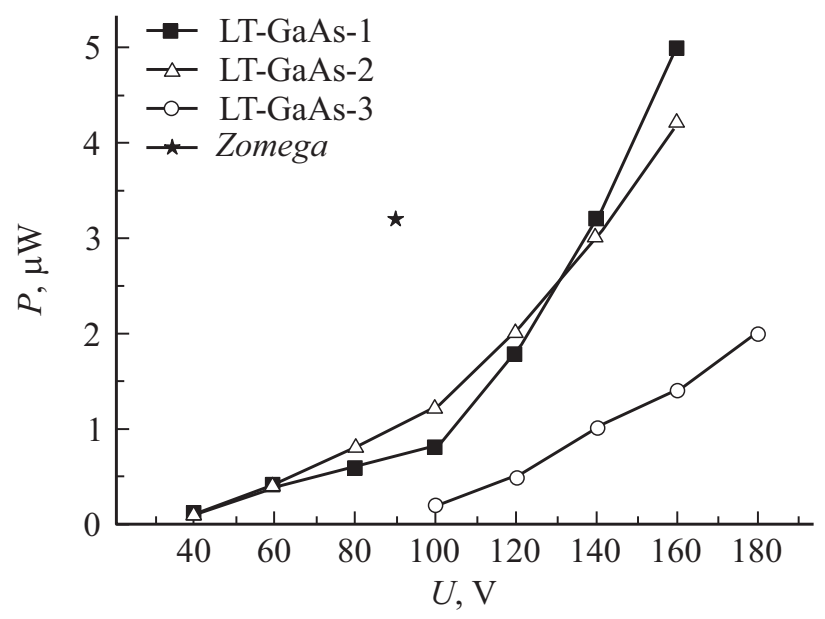

Pис. 1. Мощность THz-отклика ФПА в зависимости от напряжения смещения.

мость $\left.P(U)=1.6+4.5 \cdot 10^{-4} \cdot U^{2}\right)$, что согласуется с теоретическими оценками [12]. Изготовленные нами антенны обладают более высокой мощностью THz-излучения при повышенных н апряжениях смещения (выше $140 \mathrm{~V}$ ) по сравнению с антенной зарубежной фирмы Zomega и выдерживают работу при напряжениях до $160-180 \mathrm{~V}$. Кроме того, видно, что максимальный THZ-отклик мощностью 5.0 и $4.2 \mu \mathrm{W}$ наблюдался у структур LT-GaAs-1 и LT-GaAs-2. Вероятнее всего, это связано с тем, что постростовый отжиг приводит к образованию металлических кластеров As в матрице GaAs c характерными размерами от единиц до десятков нанометров и улучшает их качество, т.е. получаются четкие границы кристалла [13], которые придают материалу необходимые для эффективной генерации свойства: высокое удельное сопротивление (до $10^{8} \Omega \cdot \mathrm{cm}$ ) и чрезвычайно малое (менее $1 \mathrm{ps}$ ) время жизни носителей заряда.

Для определения спектральных характеристик THz-излучения использовалась методика терагерцевой спектроскопии временно́го разрешения. Схема экспериментальной оптической установки подробно описана в [11]. Детектором THz-волны являлась антенна типа логарифмической спирали с плазмонной структурой. Методика измерения 


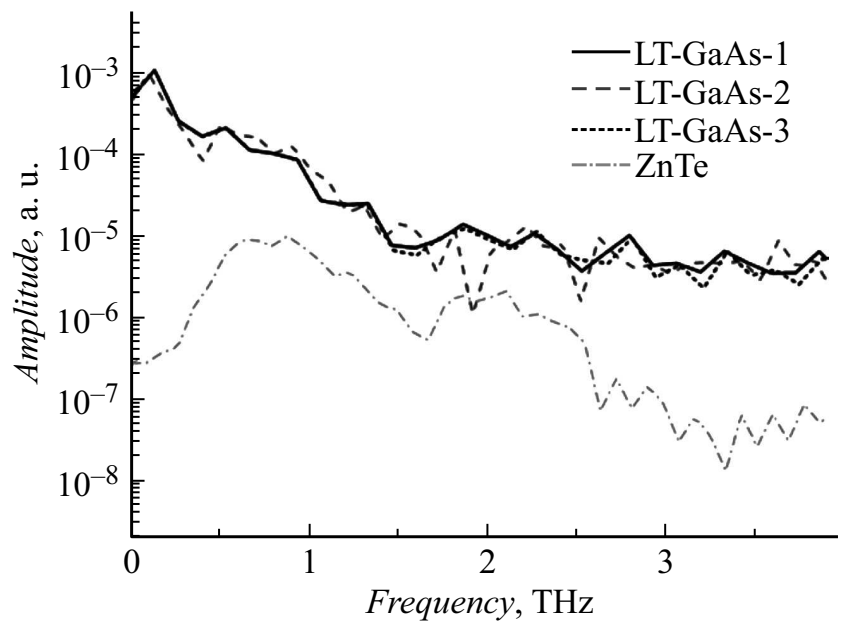

Рис. 2. Сравнение спектров ТНz-излучения терагерцевых генераторов LT-GaAs-1, LT-GaAs-2, LT-GaAs-3 и ZnTe (детектор - кристалл ZnTe). Сигнал обработан с помощью быстрого преобразования Фурье, напряжение смещения $100 \mathrm{~V}$, мощность луча накачки $300 \mathrm{~mW}$, мощность зондирующего пучка $150 \mathrm{~mW}$.

заключается в сканировании медленно изменяющегося поля THz-волны зондирующим фемтосекундным лазерным импульсом путем изменения разности оптических путей между лучами при помощи линии задержки. Таким образом при перемещении линии задержки регистрируется временна́я развертка поля THz-волны.

На рис. 2 представлены зависимости интенсивности THz-отклика ФПА на основе LT-GaAs-1,2,3 и ZnTe от частоты в диапазоне $0-4 \mathrm{THz}$ при напряжении смещения $100 \mathrm{~V}$. Проводилось сравнение характеристик созданных нами ФПА с характеристиками хорошо известного нелинейно-оптического кристалла ZnTe. Из рис. 2 видно, что основная часть THz-излучения сосредоточена в узком спектральном диапазоне от 0 до $1.5 \mathrm{THz}$ К Кроме того, для этих ФПА наблюдается два резонансных пика при значении частот $\sim 0.1$ и $\sim 0.5 \mathrm{THz}$. Максимум спектра излучения кристалла ZnTe сдвинут в сторону бо́льших частот и находится в области $1 \mathrm{THz}$. Интенсивность THz-излучения от ФПА на основе

Письма в ЖТФ, 2018, том 44, вып. 2 
LT-GaAs на два порядка превосходит интенсивность THz-излучения от нелинейного кристалла ZnTe.

Резонансную частоту для антенны можно оценить с помощью формулы [14]

$$
v_{\text {res }}=\frac{c}{2 L_{e} n},
$$

где $c$ - скорость света, $n-$ показатель преломления полупроводника на длине волны генерируемого излучения (для GaAs $n \sim \sqrt{13}$ ), $L_{e}-$ эффективная длина антенны, включающая ширину полосковой линии $D$ : $L_{e}=L+2 D(L-$ ширина антенны от внешнего края анода до внешнего края катода). Оценка дает для использованной нами топологии антенны $(L=200 \mu \mathrm{m}$ и $D=100 \mu \mathrm{m})$ частоту $0.104 \mathrm{THz}$, что согласуется с частотой резонансного пика полученных спектров. Из рис. 2 видно, что положение резонансных пиков одинаково для образцов LT-GaAs-1,2,3. Это обусловлено тем, что используемая большая эффективная длина антенны не позволяет получить более высокие частоты и выявить возможное различие во временах релаксации носителей заряда в данных образцах.

Таким образом, проведенные исследования демонстрируют, что изготовленная на основе LT-GaAs-1 ФПА обладает высокими характеристиками мощности излучения: THz-отклик мощностью $5 \mu \mathrm{W}$ при напряжении смещения $160 \mathrm{~V}$ и фототоке $14 \mathrm{~mA}$. Показано, что изготовленная антенна обдадает характеристиками, превосходящими по генерируемой мощности (в 1.5 раза) и фототоковой эффективности (в 3 раза) зарубежные аналоги. Определены оптимальные температуры отжига $\left(670-720^{\circ} \mathrm{C}\right)$ LT-GaAs для генерации высокоинтенсивных THz-волн с использованием антенн с флажковой геометрией контактов. ФПА на основе LT-GaAs c флажковой геометрией генерируют THz-сигнал в спектральном диапазоне до $1 \mathrm{THz}$ с резонансным максимумом $0.1 \mathrm{THz}$. Сравнение интенсивностей THz-излучения фотопроводящих антенн и $\mathrm{ZnTe}$ показывает, что интенсивность THz-излучения от ФПА на основе LT-GaAs приблизительно на два порядка превосходит интенсивность THz-излучения от нелинейного кристалла ZnTe.

Работа выполнена при финансовой поддержке Министерства образования и науки РФ (государственное задание № 3.7331.2017/9.10), РФФИ (проект № 16-29-14029 офи_м) и программы повышения конкурентоспособности НИЯУ МИФИ.

Письма в ЖТФ, 2018, том 44, вып. 2 


\section{Список литературы}

[1] Krishna M.G., Kshirsagar S.D., Tewari S.P. // Photodetectors / Ed. S. Gateva. InTech, 2012. Ch. 6.

[2] Gupta S., Frankel M.Y., Valdmanis J.A., Whitaker J.F., Mourou G.A., Smith F.W., Calawa A.R. // Appl. Phys. Lett. 1991. V. 59. N 25. P. 3276-3278.

[3] Smith F.W., Le H.Q., Diadiuk V.. Hollis M.A., Calawa A.R., Gupta S., Franke M., Dykaar D.R., Mourou G.A., Hsiang T.Y. // Appl. Phys. Lett. 1989. V. 54. N 10. P. 890-892.

[4] Harmon E.S., Melloch M.R., Woodall J.M., Nolte D.D., Otsuka N., Chang C.L. // Appl. Phys. Lett. 1993. V. 63. N 16. P. 2248-2250.

[5] Liu T.-A., Tani M., Nakajima M., Hangyo M., Pan C.-L. // Appl. Phys. Lett. 2003. V. 83. N 7. P. $1322-1324$.

[6] Warren A.C., Woodall J.M., Kirchner P.D., Yin X., Pollak F., Melloch M.R., Otsuka N., Mahalingam K. // Phys. Rev. B. 1992. V. 46. N 8. P. 4617-4620.

[7] Левашова А.Е., Пастор А.А., Сердобинщев П.Ю., Чалдышев В.В. // Письма в ЖТФ. 2014. Т. 40. В. 12. C. 37-43.

[8] Youn D.-H., Lee S.-H., Ryu H.-C., Jung S.-Y., Kang S.-B., Kwack M.-H., Kim S., Choi S.-K., Baek M.-C., Kang K.-Y., Kim C.-S., Yee K.-J., Ji Y.-B., Lee E.-S., Jeon T.-I., Kim S.-J., Kumar S., Kim G.-H. // J. Appl. Phys. 2008. V. 103. N 12. P. 123528.

[9] Zhang D.H., Radhakrishnan K., Yoon S.F. // J. Cryst. Growth. 1994. V. 135. N 3-4. P. 441-446.

[10] Берт Н.А., Вейнгер А.И., Вилисова М.Д., Голощапов С.И., Ивонин И.В., Козырев С.В., Куницын А.Е., Лаврентьева Л.Г., Лубышев Д.И., Преображенский В.В., Семягин Б.Р., Третьяков В.В., Чалдышев В.В., Якубеня М.П. // ФTT. 1993. T. 35. В. 10. С. 2609-2625.

[11] Галиев Г.Б., Пушкарёв С.С., Буряков А.М., Билык В.Р., Мишина Е.Д., Климов Е.А., Васильевский И.С., Мальцев П.П. // ФТП. 2017. Т. 51. В. 4. C. $529-534$.

[12] Kim J.O., Lee S.J., Yee D.S., Noh S.K., Shin J.H., Park K.H., Kang C., Kee C.-S., Kim D.W., Kim J.S. // J. Korean Phys. Soc. 2011. V. 58. N 5. P. 1334-1338.

[13] Kasai S., Watanabe M., Ouchi T. // Jpn. J. Appl. Phys. 2007. V. 46. N 7A. P. 4163-4165.

[14] Yano R., Gotoh H., Hirayama Y., Miyashita S., Kadoya Y., Hattori T. // J. Appl. Phys. 2005. V. 97. N 10. P. 103103. 